\title{
Effect of age on treatment decisions in low-grade glioma
}

\author{
Charles J Vecht
}

\begin{abstract}
The proper treatment of low-grade glioma is unclear and major uncertainties include the timing of therapy, the need for extensive surgery, or the application of radiotherapy. Although prospective trials are in progress, it may be years before results become available, as the five-year survival of low-grade glioma is around $45 \%$ or more. Age is an important prognostic factor in malignant glioma, but its implications for decisions on treatment have not yet been addressed in guidelines. This review examines the interaction between age and the results of applied treatment, based on data from published series. The available evidence suggests that, in younger patients, whether treatment is started early or late does not seem to affect long-term survival substantially. For patients under 35 years of age, more radical surgery appears to be beneficial, while radiation does not seem to improve the outcome. For patients who are 35 years and older, surgery and radiotherapy seems to produce better survival rates. The age of the patients should therefore be considered when decisions on the treatment of supratentorial, non-pilocytic, low-grade gliomas. For patients under 35 years of age who have either epilepsy or a surgically inaccessible tumour, it is advisable to defer treatment. The tumour should be largely excised, if possible. Following any surgery, radiotherapy should be withheld in this age group. For patients over 35 years of age, early treatment, including biopsy or surgery followed by radiotherapy, should not be delayed. Because of more prolonged survival, and to prevent neurotoxicity, radiation fields should be limited to the tumour bed and not include the whole of the brain. Future trials need to establish whether age is a crucial factor in deciding the timing and extent of treatment in patients with lowgrade glioma.
\end{abstract}

(F Neurol Neurosurg Psychiatry 1993;56:1259-1264)

The most common primary brain tumours of adult life are gliomas, which are classified as being either low grade or high grade. Highgrade gliomas represent about $80 \%$, the remaining $20 \%$ being low grade. Knowledge of the treatment of high-grade gliomas is more extensive than that for low-grade gliomas. A large body of prospective trials over the past 15 years has provided a well founded rationale for current treatment, which defines the roles of surgery, radiotherapy, and chemotherapy. ${ }^{1-9}$

The management of low-grade malignant glioma, however, is still controversial. All the information that we have comes from a limited number of retrospective studies. The uncertainties that are encountered include all the major decisions about treatment, such as the timing of the treatment-when should we treat? If surgery is performed, how extensive should it be? Should radiotherapy be given? These uncertainties are reflected in conflicting opinions on proper management.

Some have advocated delaying treatment, particularly if patients have epilepsy as their only symptom, and have CT features compatible with low-grade glioma. ${ }^{1011}$ Others have suggested performing immediate biopsy or surgery in all cases, followed by either radiotherapy ${ }^{12}$ or no radiotherapy at all. ${ }^{13}$ This controversy can obviously only be resolved by prospective studies, but, as the five-year survival rate for both methods varies between 45 and $65 \%$, it may be many years before unbiased figures are available. The age of the patient is a well known independent prognostic factor in high-grade glioma, but the effect of age as a substantial factor in making decisions about the treatment of lowgrade glioma has never been addressed. In this review, we will examine the prognostic value of age on outcome in patients with lowgrade glioma, and particularly its interaction with the results of applied treatment, and how this interaction affects the prognosis. Based on this analysis and with due reservations, we believe that there are data which provide information about when a conservative policy may be justified, or when early treatment, including surgery and radiotherapy, seems warranted.

Type of glioma

Only non-pilocytic, low-grade gliomas of the 
cerebral hemisphere are considered here. For some gliomas, such as optic gliomas, which are frequently associated with neurofibromatosis, thalamic gliomas, or brainstem gliomas, the site clearly restricts treatment options. The various locations of these tumors also often carry with them dissimilarities in their biological behaviour. For example, cerebellar gliomas behave differently from supratentorial tumours with the same histology, but there is no argument that excision is the best treatment for juvenile cerebellar gliomas, leading to a 10-year survival rate of more than $80 \% .^{14-16}$ Pilocytic astrocytomas of the cerebral hemispheres form a special group about which there is also consensus that surgery is sufficient, if a gross total removal of tumour can be achieved, producing a five-year survival rate of $85 \%$ and a 10 year survival rate of about $80 \% .17-19$

Non-pilocytic astrocytomas of the cerebral hemispheres are the most frequent type of low-grade gliomas and they comprise the subject of the present controversy. These include fibrillary, protoplasmatic, and gemistocytic, low-grade astrocytomas. Pure oligodendrogliomas and mixed oligoastrocytomas will not be discussed here.

\section{Prognostic factors}

The prognosis for patients with low-grade glioma depends on a number of independent factors. These are the age of the patient, the performance status (changes in neurological function or personality-see below) at the time of treatment, the grade of histology, the extent of surgery, and the application of radiotherapy (table 1 ).

Because most studies in low-grade glioma are retrospective and of relatively small size, the evidence for the effect of these factors is not as strong as has been shown in high-grade

Table 1 Independent prognostic factors in low-grade glioma *

\begin{tabular}{lllllll}
\hline & $\begin{array}{l}\text { No of } \\
\text { patients } \\
\text { studied }\end{array}$ & $\begin{array}{l}\text { Grade of } \\
\text { tumour }\end{array}$ & Age & $\begin{array}{l}\text { Performance } \\
\text { status }\end{array}$ & $\begin{array}{l}\text { Extent of } \\
\text { surgical } \\
\text { resection }\end{array}$ & $\begin{array}{l}\text { Radio- } \\
\text { therapy }\end{array}$ \\
\hline Laws et al, $1984^{20}$ & 461 & + & + & + & + & + \\
Garcia et al $1985^{21}$ & 86 & + & - & ND & + & + \\
Piepmeier, $1987^{22}$ & 60 & ND & + & ND & - & - \\
Medbery et al, $1988^{23}$ & 50 & - & + & ND & - & + \\
Shaw et al, $1989^{19}$ & 126 & + & + & ND & + & + \\
Sofietti et al $1989^{24}$ & 85 & ND & - & + & + & - \\
North et al $1990^{25}$ & 77 & - & + & + & + & - \\
\hline
\end{tabular}

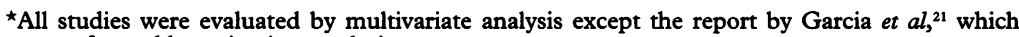
was performed by univariate analysis.

†According to dose of radiation $(p=0.07)$.

+ Denotes the presence, - the absence of a significant correlation.

$\mathrm{ND}=$ no data.

Table 2 Five-year survival in relation to age for low-grade glioma

\begin{tabular}{|c|c|c|c|c|c|}
\hline \multirow[b]{2}{*}{ Study } & \multicolumn{5}{|c|}{ Percentage of survivors at age (years) } \\
\hline & $0-19$ & $18-29$ & $30-39$ & $40-49$ & $50+$ \\
\hline Scanlon and Taylor, $1979^{29}$ & 80 & & & & ND \\
\hline Laws et al, $1984^{20}$ & 83 & & 35 & & 12 \\
\hline Medbery et al, $1988^{23}$ & ND & & & & \\
\hline Soffietti et al, $1989^{24}$ & ND & 22 & 23 & 30 & 42 \\
\hline North et al, $1990^{25}$ & 79 & & 53 & & 32 \\
\hline
\end{tabular}

$\mathrm{ND}=$ no data. glioma. The largest study of low-grade glioma identified all known prognostic factors and consisted of 461 patients, spanning a period of 40 years or more from the Mayo Clinic. ${ }^{20}$ The smaller studies could not always distinguish all factors, ${ }^{1921-25}$ but their size may be responsible. The influence of these prognostic factors on the length of survival is discussed below, followed by an examination of their interaction, particularly the effect of age on the outcome of applied treatment in lowgrade glioma.

\section{Age}

Patients with intrinsic supratentorial tumors differ in the length of their survival, depending on their age at the time when their tumour is diagnosed. ${ }^{26}$ It is well established that younger patients with high-grade, malignant glioma with identical histology have a better prognosis than elderly patients. Patients under 40 years with anaplastic astrocytoma have a median survival rate of more than three years and those with glioblastoma multiforme, about 18 months. For those between 40 and 60 years of age, the median survival rate for both tumours is 24 and nine months, respectively, but in patients over 60 years there is no difference in clinical outcome, as both tumours have a median survival rate of five to six months following surgery and radiotherapy. ${ }^{2}$ In low-grade glioma also, the age of the patient is a strong and independent prognostic factor for survival as can be seen from tables 1 and 2 .

Patients younger than 20 years with lowgrade glioma have a five-year survival rate of $80 \%$ or more; for those between 20 and 50 years old, it is $35-60 \%$, but for patients over 50 years it falls to $30 \%$ or less (table 2). ${ }^{20} 232526$ Medbery et al ${ }^{23}$ noted a substantial decrease in survival for each decade of age; patients over 40 did particularly poorly. Over 40 years of age, patients had a five-year survival rate of $28 \%$ and, after 10 years, none were alive, which is in sharp contrast with patients under 40, in whom these figures are $63 \%$ and $48 \%$.

In the study by Laws $e t a l{ }^{20}$ a four-tiered prognostic score was given, based on the simultaneous presence of several independent prognostic factors including age and performance status. If patients were over 40 years old they already belonged to the poor prognosis group, even if they otherwise had favourable prognostic factors. Only in two studies was no significant relationship between age and outcome found. ${ }^{21} 24$

\section{Performance status}

The performance status (personality, cognition, and neurological function) of the patient is another independent prognostic factor. In the three studies in which the effect of performance at the time of surgery was examined in relation to outcome, a positive correlation was observed. ${ }^{202425} \mathrm{~A}$ better performance status or neurological status at 
the time of treatment will lead to longer survival. ${ }^{202425}$ If patients have moderate or severe performance deficits, their five-year survival is $9-16 \%$ compared with $38-42 \%$ for patients with a good performance status namely, no changes in consciousness or personality at the time of surgery. ${ }^{20}$ Patients with the best performance status often have epilepsy as their only sign of low-grade glioma. In Soffietti's study, patients with a postoperative Karnofsky performance score of $90-100$ or $70-80$ had a better median survival rate compared with those with lower scores. ${ }^{24}$

\section{Extent of surgery}

A more difficult issue is the question of the extent of surgery. In three of the five studies in which the factor was analysed, more extensive surgery correlated with longer survival. ${ }^{2024} 25$ In two other studies, such a relationship could not be confirmed, which may be related to the small sample sizes. ${ }^{22}{ }^{23}$ As the assessment of the extent of surgery in these series was based on surgical records and not on preoperative and postoperative CT or MRI, these estimations may be considered to be rather inaccurate. Nevertheless, other authors found a similar trend, that more extensive surgery produces longer survival. ${ }^{135}$ Overall in low-grade glioma, extensive surgery produces a five-year survival rate of $50-90 \%$, limited resection without radiotherapy, between 21 and $34 \%$, and limited resection with radiotherapy, between 35 and $54 \%$ (table 3 ).

A separate question is whether extensive surgery would influence postoperative neurological function. Although it seems logical that more extensive surgery would lead to worse postoperative function, the reverse seems to be true. Prospective studies performed in relatively small series of patients indicate that more complete resections in low-grade and high-grade gliomas produce a better postoperative performance status and neurological status. ${ }^{135} \mathrm{We}$ found similar data in a large, albeit retrospective, series. ${ }^{27}$

Imaging, before and after surgery, is currently considered to be necessary for reliable estimation of the degree of tumour removal. The availability of CT and MRI in combination with stereotactic techniques also enables the surgeon to delineate the tumour

Table 3 Effect of treatment on five-year survival

\begin{tabular}{|c|c|c|c|}
\hline \multirow[b]{2}{*}{ Study } & \multirow{2}{*}{$\begin{array}{l}\text { Survival } \\
\text { after } \\
\text { extensive } \\
\text { surgery (\%) }\end{array}$} & \multicolumn{2}{|c|}{ Survival after limited surgery (\%) } \\
\hline & & $\begin{array}{l}\text { Without } \\
\text { radiotherapy }\end{array}$ & $\begin{array}{l}\text { With } \\
\text { radiotherapy }\end{array}$ \\
\hline $\begin{array}{l}\text { Fazekas, } 1977^{28} \\
\text { Leibel et al, } 1975^{36} \\
\text { Laws et al, } 1984^{20} \\
\text { Sofietti et al, } 1989^{24} \\
\text { Shaw et al, } 1989^{19} \\
\text { Garcia et al, } 1985^{21 \star}\end{array}$ & $\begin{array}{c}90 \dagger \\
100 \dagger \\
61 \\
51 \\
52 \\
\text { ND }\end{array}$ & $\begin{array}{l}32 \\
23 \\
34 \S \\
\text { ND } \\
\text { ND } \\
21 \ddagger\end{array}$ & $\begin{array}{l}54 \\
35 \\
495 \\
\text { ND } \\
\text { ND } \\
50 \pm\end{array}$ \\
\hline
\end{tabular}

^Percentages as read from the survival curve.

Including cerebellar tumours.

$\bigcap_{\mathrm{p}}=0.05$
$\ddagger \mathrm{p}=0.02$ accurately, while the application of new methods has improved and refined tumour excision.

\section{Radiotherapy}

The effect of radiotherapy on low-grade gliomas is uncertain, although overall results indicate that it prolongs survival. In four of the seven studies in table 1 , the application of radiotherapy proved to be an independent prognostic factor. There are virtually no data on the effect of radiotherapy in patients who have undergone a complete excision of the tumour, because radiotherapy is withheld in most of these patients. Overall results in patients who had limited treatment indicate that the delivery of radiotherapy prolongs survival from $21-34 \%$ to $35-54 \%$ (table 3 ).

There are indications that the size of the radiation dose is not insignificant. In the study by Shaw et al, ${ }^{19}$ a median dose of 4900 cGY (range 600-5000 cGy) did not affect survival, whereas the prognosis improved if patients received a median dose of $5900 \mathrm{cGy}$ (range 5360-6500 cGy).

In the report by Sofietti et al the survival rate at one year was $100 \%$ and at three years, $73 \%$ in the group that received doses over 4000 cGy. Following lower doses or no radiation treatment at all, the figures were $91 \%$ and $40 \%$, respectively. ${ }^{24}$ Medbery et $a l^{23}$ found that radiotherapy produced longer survival if the dose was over $5500 \mathrm{cGy}$. A positive dose-response for radiotherapy was also observed by Fazekas. ${ }^{28}$

\section{Interaction of age with treatment}

What about the effect of age in combination with either surgery or radiotherapy? Only a few studies have addressed this issue in lowgrade glioma. In the study of Laws et al, ${ }^{20}$ it was found that total resection produced a 10year survival rate of $69 \%$ or more but following subtotal removal, the survival rate fell to $43 \%$ after 10 years. Nevertheless, total resection was done in only $20 \%$ of these patients. ${ }^{20}$ The effect of surgery was also considered in relation to the age and performance status of the patient, and a four-tiered score was assigned, depending on these two factors. If patients were over 40 years, even if they had a good performance status with epilepsy as their only sign, they were given a high score. For patients younger than 40 years and a good performance status, the effect of radical surgery was clear, leading to better 10-year and 15-year survival rates. For patients over 40 years or with poor neurological function, the effect of total resection was less conspicuous and could not be distinguished in outcome from limited surgery. ${ }^{20}$

The same analysis was done in relation to radiotherapy. In this case, however patients under 40 years old did not survive longer than older patients. When patients had higher scores, radiotherapy appeared to be more effective, especially when survival at five years was considered. ${ }^{20}$ Garcia et $a l^{21}$ also found 
that the addition of radiotherapy did not make any difference in younger patients aged 30 years or less, whereas in older patients the five-year survival rate was $18 \%$ without, and $60 \%$ with, radiation, indicating that patients over 30 years of age did benefit from radiotherapy (table 4)..$^{21}$

More recently, Shaw et al ${ }^{19}$ similarly found that radiotherapy only helped the outcome when patients were 35 years or older (table 4). In these patients the five-year survival rate was $67 \%$ and, after 10 years, $45 \%$. Without or with low-dose radiotherapy these figures were reduced to $37 \%$ and $5 \%$ respectively. In patients younger than 35 years, survival rates were similar whether or not radiotherapy was given (table 4 ). When younger patients were subdivided into two groups aged 3-27 and 28-34 years, there were no significant differences between the groups, irrespective of whether they received radiotherapy or not. ${ }^{19}$

\section{Limited-volume versus whole-brain radiotherapy}

After two decades of whole-brain radiotherapy, with or without boost radiation to the original tumour field, limited fields again seem to be preferred to whole-brain fields for low-grade and high-grade gliomas. This change in application, however, is not based on controlled series, and, in fact, comparisons of the effect of limited versus whole brain radiation for glioma are scarce. In the study by North et al, ${ }^{25}$ there was no improvement in survival with whole-brain radiation compared with limited fields. In another report, patients who received larger treatment volumes actually did worse compared with those treated with small doses of radiation. ${ }^{29}$

A serious drawback of radiotherapy to the brain is neurotoxicity. The acute effects are almost negligible with the radiation regimens now used for patients with brain tumours. Clinical signs of late radiotoxicity may become apparent after one or two years, however, and can thus generally only be expected to occur in so-called 'long-term' survivors. There are virtually no studies on late radiation damage to the brain in patients with lowgrade glioma. In one report ${ }^{30}$ of high-grade malignant glioma, there were nine $(5 \cdot 6 \%)$ long-term survivors who had mainly undergone whole-brain radiotherapy, together with chemotherapy, of whom three became demented without evidence of tumour recurrence, and two had significantly impaired short-term memory function or gait apraxia. Only three of these long-term survivors could function independently. In another report on patients with malignant astrocytoma who previously had all been treated with a combination of surgery, whole-brain radiation, and chemotherapy, $4 \%$ (eight patients) lived longer than two years. The three longest surviving patients developed diffuse cortical dysfunction with associated cortical atrophy. ${ }^{31}$ Hochberg and Slotnic made similar observations in 13 survivors of astrocytic neoplasms who had survived for a year. All patients demonstrated difficulties in attention, immediate problem solving and tactile performance indicating diffuse or generalised brain damage. ${ }^{32}$ Mental retardation was specifically addressed in one series of low-grade cerebral astrocytomas. ${ }^{25}$ Overall, $80 \%$ of short-term survivors and $67 \%$ of long-term survivors were intellectually and physically intact, without major neurological deficit. In this series, radiotherapy was mainly delivered as a limited field. There appeared to be no correlation in this study between the incidence of mental retardation and radiation treatment or type of surgery. ${ }^{25}$

The evidence seems to suggest that late brain damage frequently occurs in long-term survivors who have been treated with wholebrain irradiation.

\section{Timing of therapy}

Two-thirds of patients with low-grade glioma present with epilepsy but without other neurological signs or symptoms. CT often discloses a non-enhancing lesion and, on MRI, a diffuse enhancing lesion following the application of gadolinium is usually seen. It is left to the physician's discretion as to whether these tumours are biopsied and excised, or whether the patients are just monitored and treated with anticonvulsants alone.

Although it is very hard to compare patients who did or did not have surgery, available data do not suggest that the timing affects the outcome to a large extent. ${ }^{11}$ The younger the patient, however, the longer the interval before intervention becomes necessary. Radiographic changes of malignant transformation occurred only in patients over 45 years at the time of diagnosis. ${ }^{11}$ In the study by Smith et al, ${ }^{33}$ it was observed that, in younger patients who presented with epilepsy only, early surgery or treatment with radiotherapy did not affect survival. As yet unexplained, age-related differences in tumour-growth control may explain the strong impact of age as a prognostic factor. ${ }^{34}$ These biological differences may also be responsible for the observed interaction of age with the effects of treatment. In younger

Table 4 Interaction of age with outcome of treatment in low-grade glioma

\begin{tabular}{|c|c|c|c|c|c|c|}
\hline & \multicolumn{3}{|c|}{ Five-year survival for younger patients (\%) } & \multicolumn{3}{|c|}{ Five-year survival for older patients(\%) } \\
\hline & $\begin{array}{l}\text { Surgery alone } \\
\text { or low-dose } \\
\text { radiotherapy }\end{array}$ & $\begin{array}{l}\text { Surgery } \\
\text { and } \\
\text { radiotherapy }\end{array}$ & $p$ & $\begin{array}{l}\text { Surgery alone } \\
\text { or low-dose } \\
\text { radiotherapy }\end{array}$ & $\begin{array}{l}\text { Surgery } \\
\text { and } \\
\text { radiotherapy }\end{array}$ & $p$ \\
\hline Garcia et al, 1985'21 * & 50 & 30 & 0.51 & 18 & 60 & 0.002 \\
\hline Shaw et al, $1989^{19} \dagger$ & 53 & 70 & 0.69 & 37 & 67 & 0.008 \\
\hline
\end{tabular}


patients with low-grade glioma, the beneficial effect of age is so strong that therapy seems to have a marginal effect, with the exception of surgical excision. In the older age group, the effect of treatment becomes more important. Low-grade glioma in patients over 40 years is not a benign disease and this probably explains the observed favourable effects of radiotherapy on the length of survival.

\section{Conclusions}

Summarising the findings on outcome in patients with low-grade gliomas, a few general conclusions emerge.

Firstly, age is an independent prognostic factor. Secondly, in younger patients, starting treatment early or late does not seem to influence long-term survival substantially. Thirdly, if extensive surgery is performed, in the main, it leads to a better outcome in patients under 35 years of age. Fourthly, radiotherapy only seems to produce a longer survival in patients over 35 years of age.

Our recommendations are guided by these results and are essentially based on the patient's age at the time of presentation.

For patients under 35 years of age, and who are suspected of low-grade glioma because of clinical presentation and imaging studies, we believe that it is responsible to monitor their progress without surgical interaction, particularly if only a subtotal resection can be done. If extensive resection can be performed safely, we would favour this approach. We would then prefer to follow the patient without administering radiotherapy. Surgery should always be seriously considered in the younger age group, however, and is often mandatory in certain conditions for either diagnostic or therapeutic reasons. These include clinical neurological deterioration, impending herniation, hydrocephalus, uncontrollable seizures, or the need for a tissue diagnosis.

For patients of 35 years and older, we suggest that treatment should not be deferred. Under these circumstances we would favour early biopsy or surgery in all cases. The extent of surgery is probably important, although not much as it is in younger patients, and a more conservative approach may be warranted. Independent of the extent of surgery, we would advise radiotherapy for all patients in this age group. Because these patients have a five-year survival of $30 \%$ or more, the effects of late radiation damage may develop, particularly when whole-brain radiation is delivered. This is an additional argument for treating these patients with limited-field radiation to the tumour bed with large margins. Extra motivation not to delay treatment in this age group is that patients who show a non-enhancing lesion on CT may nevertheless turn out to be harbouring a high-grade glioma, as shown by histology. In particular, patients between 30 and 50 years of age with a non-enhancing lesion on $\mathrm{CT}$ have about a $50 \%$ likelihood of high-grade malignant glioma. ${ }^{35}$
Of course, we realise that these recommendations are based on retrospective studies and that unbiased data are needed. The age limits are somewhat arbitrary and there should be room for alternative options in individual patients, because the biological behaviour of low-grade glioma is difficult to predict. Nevertheless, we believe that our suggestions provide considered and justifiable guidelines for the time being. Although some randomised studies in low-grade glioma are underway and their results are eagerly awaited, important questions still remain. Prospective trials should establish whether age is a crucial factor in deciding the appropriate timing and extent of treatment within each age group. One issue for patients younger than 35 years with epilepsy only, is whether a 'wait-and-see' strategy is desirable or whether early surgery is warranted, and whether or not this should be followed by radiotherapy. For patients over 35 years with low-grade glioma, another question is whether one should aim for as complete a resection as possible, or whether more limited excision would be sufficient.

This paper was presented on 17 May 1991 in Nijmegen, The Netherlands, in honour of the retirement of Professor JL Slooff, neuropathologist.

1 Ammirati M, Vick N, Liao Y, Ciric I, Mikhael M. Effect of the extent of surgical resection on survival and quality of life in patients with supratentorial glioblastomas and anaplastic astrocytomas. Neurosurgery 1987;21:201-6.

2 Chang $\mathrm{CH}$, Horton J, Schoenfeld $\mathrm{D}$, et al. Comparison of postoperative radiotherapy and combined postoperative radiotherapy and chemotherapy in the multidisciplinary radiotherapy and chemotherapy in the multidisciplinary manageme

3 Ciric I, Ammirati M, Vick N, Mikhael M. Supratentorial gliomas: Surgical considerations and immediate postoperative results. Gross total resection versus partial resection. Neurosurgery 1987;21:21-6.

4 European Organization for Research on Treatment of Cancer (EORTC) Brain Tumor Group. Evaluation of CCNU, VM-26 plus CCNU and procarbazine in supratentorial brain gliomas. $\mathcal{F}$ Neurosurg 1981;55:27-31.

5 Fadul C, Wood J, Thaler H, Galicich J, Patterson RH, Posner JB. Morbidity and mortality of craniotomy for excision of supratentorial gliomas. Neurology 1988;38: 1374-9.

6 Green SB, Byar DP, Walker MD, et al. Comparisons of carmustine, procarbazine and high-dose methylprednisolone as additions to surgery and radiotherapy for the treatment of malignant glioma. Cancer Treat Rep 1983; treatment

7 Kristiansen K, Hagen S, Kollevold T, et al. Combined modality therapy of operated astrocytomas grade III and IV. Confirmation of the value of postoperative irradiation and lack of potentiation of bleomycin on survival time. Cancer 1981;47:649-52.

8 Walker MD, Alexander E, Hunt WE, et al. Evaluation of BCNU and/or radiotherapy in treatment of anaplastic gliomas. F Neurosurg 1978;49:333-43.

9 Walker MD, Green SB, Byar DP, et al. Randomized comparisons of radiotherapy and nitrosoureas for the treatment of malignant glioma after surgery. $N$ Engl $f$ Med ment of malignant

10 Cairncross JG, Laperriere NJ. Low-grade glioma. To treat or not to treat? Arch Neurol 1989;46:1238-9.

11 Recht LD, Lew R, Smith TW. Suspected low-grade glioma: is deferring treatment safe? Ann Neurol 1992;31: glioma:

12 Shaw EG. Low-grade gliomas: to treat or not to treat? Arch Neurol 1990;47:1138-9.

13 Shapiro WR. Low-grade gliomas: when to treat? Ann Neurol 1992;31:437-8.

14 Winston K, Gilles FH, Leviton A, Fulchiero A. Cerebella gliomas in children. $\mathcal{F}$ Natl Cancer Inst 1977;58:833-8.

15 Gjerris F, Klinken L. Longterm prognosis in children with benign cerebellar astrocytoma. $\mathcal{F}$ Neurosurg 1978;49: 179-84.

16 Wallner KE, Gonzales MF, Edwards MSB, Wara WM, Sheline GE. Treatment results of juvenile pilocytic astrocytoma. 7 Neurosurg 1988;171:171-6.

17 Clark GB, Henry JM, McKeever PE. Cerebral pilocytic astrocytoma. Cancer 1985;56:1128-33.

18 Palma L, Guidetti B. Cystic pilocytic astrocytomas of the 
cerebral hemispheres. Surgical experience with 51 cases and long-term results. $\mathcal{F}$ Neurosurg 1985;62:811-5.

19 Shaw EG, Daumas-Duport C, Scheithauer BW, et al. Radiation therapy in the management of low-grade supratentorial astrocytomas. $f$ Neurosurg 1989;70: 853-61.

20 Laws ER, Taylor WF, Clifton MB, Okaziki H Neurosurgical management of low-grade astrocytoma of the cerebral hemispheres. $₹$ Neurosurg 1984;61:665-73.

21 Garcia DM, Fulling KH, Marks JE. The value of radiation therapy in addition to surgery for astrocytomas of the adult cerebrum. Cancer 1985;55:919-27.

22 Piepmeier JM. Observations on the current treatment of low-grade astrocytic tumors of the cerebral hemispheres. $\mathcal{f N e u r o s u r g} 1987 ; 67: 177-81$.

23 Medbery CA, Straus KL, Steinberg SM, Cotelingam JD, Fisher WS. Low-grade astrocytomas: treatment results and prognostic variables. Int 7 Radiat Oncol Biol Phys 1988;15:837-41.

24 Soffietti R, Chiò A, Giordana MT, Vasario E, Schiffer D. Prognostic factors in well-differentiated cerebral astrocytomas in the adult. Neurosurgery 1989;24:686-92.

25 North CA, North RB, Epstein JA, Piantadosi S, Wharam MD. Low-grade cerebral astrocytomas. Survival and MD. Low-grade cerebral astrocytomas. Survival and quality

26 Hutton JL, Smith DF, Sandemann D, et al. Development of prognostic index for primary supratentorial intracerebral tumours. $\mathcal{f}$ Neurol Neurosurg Psychiatry 1992;55 $271-4$

27 Vecht ChJ, Avezaat CJJ, Putten WLJ van, Eijkenboom WHM, Stefanko SZ. The influence of the extent of surgery on the postoperative neurological function and survival in malignant glioma. $f$ Neurol Neurosurg Psychiatry 1990;53:466-71.

28 Fazekas JT. Treatment of grades I and II brain astrocytomas. The role of radiotherapy. Int $\mathcal{F}$ Radiat Oncol Biol Phys 1977;2:661-6.

29 Scanlon PW, Taylor WF. Radiotherapy of intracranial astrocytomas: Analysis of 417 cases treated from 1960 astrocytomas. Ansis of 417 cases treated

30 Imperato JP, Paleologos NA, Vick NA. Effects of treatment on long-term survivors with malignant astrocyment on long-term survivors with

31 Lieberman AN, Hoo Foo S, Ransohoff J, et al. Long term survival among patients with malignant brain tumors. Neurosurgery 1982;10:450-3.

32 Hochberg FH, Slotnick B. Neuropsychologic impairmen in astrocytoma survivors. Neurology 1980;30:172-7.

33 Smith DF, Hutton JL, Sandemann D, et al. The prognosis of primary intracerebral tumours presenting with epilepsy: the outcome of medical and surgical management. I Neurol Neurosurg Psychiatry 1991;54: 915-20.

34 Jennings MT, Asadourian LLH, Jennings VDVL, Shapiro JR, Thaler HT. Factor analysis of the immunophenotypes of astrocytomas and malignant gliomas: correlatypes of astrocytomas and malignant gliomas: correlations with tumor grade

35 Chamberlain MC, Murovic JA, Levin VA. Absence of contrast enhancement on CT brain scans of patients with supratentorial malignant gliomas. Neurology 1988; 38:1371-4.

36 Leibel SA, Sheline GE, Wara WM, Boldrey EB, Nielsen $\mathrm{SL}$. The role of radiation therapy in the treatment of astrocytomas. Cancer 1975;35:1551-7. 